\title{
Studiemateriaal Discipline farmacologie
}

\author{
Th.P.G.M. de Vries, L. van Bortel, P.A. de Graeff, J.M.A. Sitsen
}

\section{Besproken studiemateriaal}

1. Pharmacology, Rang, Dale, Ritter.

2. Clinical Pharmacology, Laurence, Bennett, Brown.

3. Human Pharmacology; Molecular to Clinical. Brody, Larner, Minneman.

4. Medical Pharmacology at a Glance, Neal.

5. Farmacologie, Sitsen, Breimer, Cools, Saxena, Smits, Van Wimersma Greidanus.

6. Algemene Farmacotherapie, Wesseling, Neef, De Graeff, eindredactie.

7. Farmacotherapie op Recept, Ufkes, redactie, Koopmans, Guchelaar, Venema.

8. Farmacotherapie op Maat, De Vries, Henning, Van Bortel.

9. Guide to Good Prescribing; a Practical Manual, De Vries, Henning, Hogerzeil, Fresle.

10. Farmacotherapeutisch Kompas 2000/2001, Van der Kuy, redactie

\section{Inleiding}

Traditioneel wordt de farmacologie onderverdeeld in algemene farmacologie en speciële farmacologie. De algemene farmacologie omvat de concepten die ten grondslag liggen aan de effecten van geneesmiddelen (farmacodynamiek), en aan de opname en uitscheiding van geneesmiddelen in het lichaam (farmacokinetiek). De speciële farmacologie beschrijft deze eigenschappen voor specifieke geneesmiddelen(groepen). Recentelijk is ook meer inzicht verkregen in hoe die kennis toegepast moet worden bij het kiezen en voorschrijven van geneesmiddelen: farmacotherapie. Ter ondersteuning hiervan worden geneesmiddelencompendia samengesteld: korte beschrijvingen van de eigenschappen van (alle) verkrijgbare geneesmiddelen.

Bij de bespreking is een keus gemaakt voor enkele boeken op het gebied van de farmacologie en farmacotherapie, en een compendium. De keuze is bepaald door de mate waarin de boeken worden gebruikt in het onderwijs, de spreiding over de drie onderdelen, en door persoonlijke voorkeuren van de auteurs. De vele bestaande geneesmiddelenformularia met specifieke far- macotherapieadviezen zijn buiten beschouwing gelaten. De hoofdstukken 'klinische farmacologie' in sommige leerboeken interne (Souhami), naslagwerken (Merck Manual) of universitaire syllabi en readers zijn tevens buiten beschouwing gelaten, omdat deze de stof veelal volstrekt onvoldoende beschrijven voor (zelf)studie.

Met het verdwijnen van disciplinegericht onderwijs en de opkomst van patiënt- en probleemgeoriënteerd en klinisch geïntegreerd onderwijs wordt het gebruik van leer- en studieboeken belangrijker. De studenten moeten hierbij immers meer door zelfstudie de opbouw van een vakgebied leren. Dit moet bij paraklinische disciplines zoals farmacologie, met name leiden tot begrip van de basisprocessen die ten grondslag liggen aan specifieke feiten over geneesmiddelen. Dit spaart niet alleen het geheugen, maar voorkomt tevens 'doen-zonder-te-begrijpenwaarom'-gedrag. Elke geneeskundestudent dient derhalve een goed farmacologiestudieboek te bestuderen en geregeld te raadplegen, en over de aldus verworven kennis, begrip en voorschrijfvaardigheden bij het oplossen van patiëntproblemen te worden getoetst. Het voorschrijfgedrag van nog te veel artsen geeft hiervoor voldoende aanleiding. 


\section{Beknopte bespreking}

\section{H.P. RANG, M.M. DALE, J.M. RITTER. Pharmacology. EDINBURgh: CHURCHILL LIVINGSTONE; 1992 (LEERBOEK).}

Het inmiddels bekende leerboek van Rang en Dale is klassiek van opzet. Na de algemene farmacologie wordt de farmacologie van de verschillende groepen geneesmiddelen betrekkelijk diepgaand en uitgebreid besproken. De nadruk ligt daarbij op het werkingsmechanisme, de beïnvloeding van de (patho)fysiologie, maar daarnaast komt soms ook het 'farmacologisch gereedschap' aan bod. Summier wordt ook het onderzoek met nieuwe geneesmiddelen bij de mens ter sprake gebracht. Hoewel de stof voor de Nederlandse opleiding tot basisarts hier en daar wat ver voert, is 'Rang en Dale' een prettig en didactisch goed opgezet leerboek farmacologie.

\section{D.R. LaURence, P.N. BenNett, M.J. Brown. Clinical Pharmacology. EDINBURGH: CHURCHILL LIVINGSTONE; 1997 (LEERBOEK).}

Klassiek leerboek dat inmiddels aan zijn achtste druk toe is. Het is opgesplitst in acht secties, met in de eerste twee secties aandacht voor algemene principes en in de daaropvolgende secties voor de farmacotherapie. De kracht van dit boek is de gecomprimeerde en goed leesbare tekst door een beperkt aantal auteurs (3) met op relevante plaatsen korte samenvattingen. Niet altijd duidelijk is de gemaakte indeling in indicaties, geneesmiddelgroepen en afzonderlijke geneesmiddelen, hetgeen de overzichtelijkheid niet altijd ten goede komt. Het is daarom méér geschikt voor (zelf)studiestof dan als naslagwerkwerk om een farmacotherapeutisch probleem op te lossen.

\section{T.M. BRODY, J. LARNER, K.P. MinNEMAN. Human Pharmacology; Molecular to CLINICAL. MOSBY; 1998 (LEERBOEK).}

Een derde gewijzigde druk in zeven jaar geeft aan dat dit boek in een behoefte voorziet. Hoewel van klassieke opzet (algemene en speciële farmacologie) is het klinisch gericht, zij het niet ziektebeeldgericht. Dat blijkt niet alleen uit de titel en het grote aantal artsen als co-auteur, maar tevens uit de opzet en de vijf onderdelen van de meeste hoofdstukken (Therapeutic overview, Mechanisms of action,
Pharmacokinetics, Relation of mechanisms of action to clinical response, Side effects, clinical Problems and toxicity, and New horizons). De bespreking is vrij diepgaand maar zeer helder. Samen met de voortreffelijke illustraties en de gunstige prijs is het een bijzonder aantrekkelijk studieboek.

\section{M.J. NEAL. MEDICAL PHARMACOLOGY AT A GLANCE. LONDON: BLACKWELL SCIENCE; 1997 (LEERBOEK, LECTURE NOTES).}

Dit boekje is ontstaan uit de lecture notes en de overheadsheets van een docent klinische farmacologie. De opzet is klassiek (algemene en speciële farmacologie), maar zeer origineel. Elk hoofdstuk beslaat twee tegenover elkaar gelegen pagina's. Twee derde van de linker pagina geeft een schematische, over het algemeen duidelijke, weergave van de tekst die de rest van de twee bladzijden beslaat. De eerste vier hoofdstukken behandelen aldus de algemene farmacologie. De overige hoofdstukken de speciële farmacologie. De tekst is bij deze opzet noodgedwongen kort en bondig, maar is tevens correct. Het vereist dan ook enige achtergrondkennis en begrip van de farmacologie om deze te begrijpen. Dit maakt het minder geschikt als leerboek, maar meer als naslagwerk voor zowel studenten als docenten. Na enig 'opblazen' zijn van de schema's voortreffelijke overheadsheets en 'hand-outs' te maken, die bij het onderwijs kunnen worden gebruikt.

5. J.M.A. SitSEN, D.D. Breimer, A.R. CoOls, P.R. SAXENA, J.F.M. SMITS, TJ.B. VAN WiMERSMA GREIDANUS. FARMACOLOGIE. UTRECHT: BUNGE; 1996 (LEERBOEK).

Het boek is interessant omdat het, zonder volledig te willen zijn, voor de student de belangrijkste onderwerpen uit de medische farmacologie behandelt. De auteurs hebben geopteerd voor een indeling per orgaan of systeem. Dit verhoogt aanzienlijk de inschatting van de klinische relevantie van de stof. Het boek is in de eerste plaats een farmacologieboek. Het toont structuurformules van medicijnen en werkingsmechanismen in heldere schemata. Sommige schemata zouden nog één stap verder uitgewerkt kunnen worden door de dynamische consequenties te tonen. Bijvoorbeeld: het schema van de werking van ACE-remmers stopt bij de daling van het aldosteron en de stijging van het bradykinine maar verbindt hier- 
aan niet de respectievelijke bijwerkingen van hyperkaliëmie en hoesten. De hoofdstukken bevatten ook een alinea over farmacotherapie (toepassing van medicijnen bij de mens). Dit is een sterk punt. De farmacotherapie is echter wisselend ingevuld. Zo worden duidelijke richtlijnen gegeven voor behandeling van astma en COPD, maar ontbreken richtlijnen voor hypertensie en pijnbestrijding. De referenties zijn beperkt waardoor de evidentie van bepaalde therapeutische richtlijnen niet meteen duidelijk is. De opzet van dit interessante boek noopt tot zeer regelmatige updating van de gegevens.

6. H. Wesseling, C. NEEF, P.A. DE GRAEFF, EINDREDACTIE. ALGEMENE FARMACOTHERAPIE. HOUTEN: BOHN STAFLEU VAN LOGHUM; 1999 (LEERBOEK)

Na bijna veertig jaar en zeven edities is dit boek zo langzamerhand een klassieker. Zoals de nog steeds ongewijzigde naam aangeeft, wordt gepoogd om een brug te slaan van de farmacologie naar de farmacotherapie. In de eerste twee rubrieken wordt de algemene farmacologie beschreven, voor de overige rubrieken is de indeling overwegend per orgaan of tractus. Het slaan van de brug is echter maar ten dele gelukt. Het is toch voornamelijk een (goed) farmacologieboek gebleven. De hoofdstukken bestaan voor het (over)grote deel uit besprekingen van geneesmiddelen, aangevuld met farmacotherapieadviezen. De inhoud is relevant voor de artsopleiding, maar de didactische kwaliteit is matig. Er wordt geen onderscheid gemaakt tussen relevante en minder relevante leerstof, er zijn geen samenvattingen of samenvattende overzichten, en er zijn weinig illustraties om de tekst en het geheugen te ondersteunen. Als naslagwerk voor artsen, en als studieboek voor studenten die een bijvak of keuzeproject in de farmacologie volgen, is het zeer geschikt.

7. J.G.R. UFKES, R-P. KOOPMANS, H-J. GUCHELAAR, F.J. VENEMA. FARMACOTHERAPIE OP RECEPT. ALPHEN AAN DE RIJN: VAN ZUIDEN; 2000 (GIDS VOOR PRAKTISCHE FARMACOTHERAPIE).

Het boek behandelt veel meer dan de titel doet vermoeden. Het behandelt in detail de verschillende aspecten van de farmacotherapie. Het is erg praktijkgericht, en besteedt ook aandacht aan wetgeving, terugbetaling van geneesmidde- len, het technisch correct schrijven van een recept, biofarmacie en kinetiek. Enkele oefeningen uit de dagelijkse praktijk tonen welke nuttige informatie dit kan opleveren. Sommige aspecten van farmacotherapie krijgen te weinig aandacht zoals de geneesmiddelkeuze (evidence-based pharmacotherapy) en farmaco-economie. De casuïstiek is zeer illustratief en gericht op de huisartsenpraktijk. De antwoorden op oefeningen verdienen soms wat meer uitleg.

Bij het boek zit ook een zakkompas. Het is een handig boekje dat zeer overzichtelijk is opgesteld. Het geeft ook aan wanneer een therapie het beste door een specialist kan worden ingesteld. Via beslisbomen wordt de voorschrijver naar de betere therapie geleid. Door zijn beknoptheid kan het niet alle situaties bevatten waarin een patiënt zich presenteert. Het mag dus niet als een kookboek worden gezien, maar wel als een leidraad. Elke voorgestelde therapie dient op geschiktheid voor de patiënt te worden getoetst. Het zakkompas geeft niet ten volle de reden waarom voor een bepaald medicijn werd gekozen. Voor meer details wordt geregeld verwezen naar het Farmacotherapeutisch Kompas.

8. TH.P.G.M. DE VRIES, R.H. HENNING, L. VAN BORTEL. FARMACOTHERAPIE OP MAAT. UTRECHT: BUNGE; 1998 (GIDS VOOR PRAKTISCHE FARMACOTHERAPIE).

Dit boek is een beschrijving van een praktische methode voor farmacotherapie op maat. Het bestaat uit vier hoofdstukken waarin achtereenvolgens farmacodynamische en farmacokinetische basisprincipes, het kiezen van geneesmiddelen, de systematische weg om tot een rationele keuze hiervan te komen en casuïstiek aan de orde komen. De belangrijkste algemene eindtermen met betrekking tot de farmacotherapie, zoals geformuleerd in het Raamplan 1994 artsopleiding, komen hierbij aan de orde. De beginselen die aan de orde komen zijn derhalve onmisbaar bij het onderwijs in de rationele farmacotherapie. De inhoud ervan is afgeleid van de eveneens becommentarieerde WHO Guide to Good Prescribing. Het vormt derhalve een goed alternatief wanneer de voorkeur uitgaat naar een gecomprimeerde, op de praktijk gerichte, Nederlandstalige versie. 
9. TH.P.G.M. DE VRIES, R.H. HENNING, H.V. HogerzeIL, D.A. FRESLE. GUIDE TO GOOD PRESCRIBING; A PRACTICAL MANUAL. GENEVE: WORLD HEALTH ORGANIZATION - ACTION PROGRAMME ON ESSENTIAL DRUGS; 1994 (GIDS VOOR PRAKTISCHE FARMACOTHERAPIE).

'A practical manual' geeft nauwkeurig aan waarom het gaat: een gids voor (aanstaande) artsen om rationeel en verantwoord te leren voorschrijven. Deze gids is onderdeel van het 'Action Programme on Essential Drugs' en waarschijnlijk allereerst bedoeld voor ontwikkelingslanden. Studenten in de westerse wereld kunnen echter deze gids ook met vrucht gebruiken om - nadat zij voldoende farmacologisch zijn geschoold - te leren geneesmiddelen rationeel voor te schrijven. Daartoe behoort ook een verstandige omgang met patiënt en geneesmiddel. Voorts bevat deze gids ook instructie betreffende de toepassing van geneesmiddelen (oog- en oordruppels, zetpillen, injecties, enzovoorts), een onderdeel van de praktische farmacotherapie dat helaas maar zelden aan de orde komt. Deze uiterst nuttige en praktische gids stamt uit 1994 en dat betekent dat er nog geen aandacht is besteed aan de rol die de computer kan spelen bij de praktische farmacotherapie en ook niet aan het internet als bron van informatie over geneesmiddelen.
10.J.A. VAN DER KUY, EINDREDACTEUR. FARMACOTHERAPEUTISCH KOMPAS 2000/2001; UTRECHT: COMMISSIE FARMACEUTISCHE HULP/COLLEGE VOOR ZORGVERZEKERINGEN; 2000 (COMPENDIUM).

Het Farmacotherapeutisch Kompas is een geneesmiddelencompendium primair bedoeld voor praktiserende artsen. Daardoor is het ook geen studie- of leerboek in de gebruikelijke zin. Toch is het uiterst relevant voor de opleiding. In de eerste plaats bij het leren voorschrijven van geneesmiddelen wegens de onderbouwde aanwijzingen voor het maken van een keuze, de theoretische inleidingen en de preparaatinformatie. In de tweede plaats omdat op deze wijze studenten reeds vertrouwd raken met een naslagwerk voor de praktijk. Het gratis verkrijgbaar zijn, en de jaarlijkse updates maken dat iedere student dit boek moet bezitten maar vooral (leren) gebruiken. Het Farmacotherapeutisch Kompas is ook als cd-rom verkrijgbaar (los: fl.150,-; studenten 50\% korting). Het is een bijzonder gebruikersvriendelijk programma met uitgebreide zoekfuncties en verwijzingen.

\section{De auteurs:}

Prof. dr. Th.P.G.M. de Vries is hoogleraar Farmacologie en Farmacotherapie,Afdeling Medische Farmacologie, Vrije Universiteit Amsterdam.

Prof. dr. L. van Bortel is hoogleraar Klinische Farmacologie en Farmacotherapie, Heymans Instituut voor Farmacologie, Universiteit van Gent.

Prof. dr. P.A. de Graeff is hoogleraar Farmacotherapie, Disciplinegroep Klinische Farmacologie, Rijksuniversiteit Groningen.

Prof. dr. A. Sitsen is hoogleraar Klinische Farmacologie, Disciplinegroep Medische Farmacologie, Rijksuniversiteit Utrecht. 


\begin{tabular}{|c|c|c|c|c|c|c|c|c|c|c|}
\hline \multirow[t]{2}{*}{ Beoordeelde kenmerken ${ }^{1}$} & \multicolumn{6}{|c|}{ Leerboek farmacologie } & \multicolumn{3}{|c|}{ Farmacotherapie } & \multirow{2}{*}{ 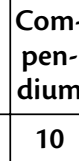 } \\
\hline & 1 & 2 & 3 & 4 & 5 & 6 & 7 & 8 & 9 & \\
\hline \multirow{2}{*}{$\begin{array}{l}\text { Relevantie voor de artsopleiding } \\
\text { Relevantie voor medische biologie/ } \\
\text { gezondheidswetenschappen }\end{array}$} & 4 & 5 & 5 & 5 & 4 & 4 & 5 & 5 & 5 & 5 \\
\hline & 5 & 4 & 4 & 3 & 4 & 4 & 2 & 2 & 2 & 3 \\
\hline Inhoudelijke kwaliteit & 5 & 4 & 4 & 4 & 4 & 4 & 4 & 4 & 4 & 4 \\
\hline Vormgeving & 4 & 5 & 5 & 4 & 5 & 4 & 5 & 4 & 4 & 4 \\
\hline Didactische kwaliteit ('studeerbaarheid') & 4 & 4 & 5 & 3 & 4 & 3 & 4 & 5 & 5 & 3 \\
\hline Geschikt als verplichte zelfstudiestof & 5 & 5 & 5 & 2 & 4 & 3 & 4 & 5 & 5 & 4 \\
\hline $\begin{array}{l}\text { Kwaliteit verwijssystematiek en } \\
\text { dekking van de materie }\end{array}$ & 4 & 4 & 4 & 3 & 3 & 4 & 4 & 3 & 3 & 4 \\
\hline Aan te bevelen om zelf aan te schaffen & 5 & 4 & 5 & 5 & 4 & 3 & 5 & 5 & 5 & 5 \\
\hline Geschiktheid voor de gehele studie & 4 & 4 & 4 & 4 & 3 & 3 & 4 & 5 & 4 & 4 \\
\hline Kwaliteit voorbeelden/casus & 4 & - & - & - & - & - & 4 & 5 & 5 & - \\
\hline Kwaliteit studieopdrachten of vragen & - & - & - & - & - & - & 4 & - & 4 & - \\
\hline $\begin{array}{l}\text { Kwaliteit antwoorden bij studie- } \\
\text { opgaven of vragen }\end{array}$ & - & - & 4 & - & - & - & 3 & - & 4 & - \\
\hline \multicolumn{11}{|l|}{ Beschrijvende kenmerken } \\
\hline Taal & $\mathrm{E}$ & $\mathrm{E}$ & $\mathrm{E}$ & $\mathrm{E}$ & $\mathrm{N}$ & $\mathrm{N}$ & $\mathrm{N}$ & $\mathrm{N}$ & $\mathrm{E}$ & $\mathrm{N}$ \\
\hline Omvang in pagina's & 830 & 710 & 1001 & 103 & 476 & 1132 & 305 & 124 & 108 & 1208 \\
\hline $\begin{array}{l}\text { Omvang (breedte maal hoogte, } \\
\text { afgerond in } \mathrm{cm} \text { ) }\end{array}$ & $19 \times 25$ & $19 \times 24$ & $21 \times 28$ & $22 \times 28$ & $19 \times 27$ & $17 \times 25$ & $16 \times 24$ & $15 \times 24$ & $21 \times 30$ & $20 \times 27$ \\
\hline Aantal delen & 1 & 1 & 1 & 1 & 1 & 1 & 2 & 1 & 1 & 1 \\
\hline Druk & 4 & 8 & 3 & 3 & 1 & 7 & 2 & 1 & 1 & 18 \\
\hline Jaar van uitgave & 1999 & 1997 & 1998 & 1997 & 1996 & 1999 & 2000 & 1995 & 1994 & 2000 \\
\hline Jaar van eerste druk & 1987 & 1980 & 1991 & 1987 & 1996 & 1961 & 1995 & 1995 & 1994 & 1982 \\
\hline Prijs (in guldens) & 165 & 155 & 103 & 50 & 124 & 225 & 95 & 65 & $\$ 25^{*}$ & $50^{* *}$ \\
\hline \multicolumn{11}{|c|}{$\begin{aligned}{ }^{1} \text { Beoordeling: } & \text { 1= zeer slecht/zeer gering/zeer ongeschikt; } 2=\text { slecht/gering/ongeschikt; } 3=\text { matig; } \\
& \text { 4= goed/groot/geschikt; } 5=\text { zeer goed/zeer groot/zeer geschikt; }-=\text { niet van toepassing } \\
& * \text { bestellen, of zonder kosten te downloaden via } w w w . w h o . i n t \text { of kopiëren } \\
& * * \text { studenten halve prijs; als student geneeskunde zonder kosten via faculteiten geneeskunde } \\
& \text { in Nederland te verkrijgen }\end{aligned}$} \\
\hline
\end{tabular}

